\title{
Diversidade etnolinguística no Brasil: a contribuição da sociolinguística de contato para o plurilinguismo
}

\author{
Gilberto Ferreira de SOUZA (D) \\ Universidade Federal Fluminense (UFF)
}

\section{RESUMO}

Esta resenha aborda a difusão do que vem sendo produzido em diversos grupos de pesquisa nos estudos de sociolinguística de contato. A despeito da fala de que o Brasil é um país monolíngue e monocultural, a realidade nos revela um país onde o plurilinguismo está manifesto em indivíduos e em diversas comunidades. De acordo com a professora da Universidade Federal Fluminense e moderadora desta mesa redonda, Mônica Savedra, essa riqueza é assinalada por contrastes e conflitos expressos pela diversidade etnolinguística e cultural presente nos mais variados grupos no país, a saber: indígenas, imigrantes, quilombolas, ciganos, comunidades surdas, contextos fronteiriços entre outros. Ainda segundo Savedra, as situações de contato não são absolutas, e sim relativas. Após a apresentação de três situações de contato que foram relatadas por três pesquisadoras de diferentes instituições, as mesmas responderam, brevemente, a importantes questões dos ouvintes sobre o tema abordado: a sociolinguística de contato.

\section{RÉSUMÉ}

Ce compte-rendu porte sur la diffusion de ce qui a été produit dans plusieurs groupes de recherche dans les études de la sociolinguistique de contact. Malgré l'affirmation selon laquelle le Brésil est un pays monolingue et monoculturel, la réalité nous révèle un pays où le plurilinguisme se manifeste chez les individus et dans les différentes communautés. Selon le professeur de l'Université Federale Fluminense et modératrice de cette table ronde, Mônica Savedra, cette richesse est marquée par les contrastes et les 


\section{REVISTA DA ABRALIN}

conflits exprimés par la diversité ethnolinguiste et culturelle présente dans les groupes les plus variés dans le pays, à savoir : indigènes, immigrants, quilombolas, gitans, contextes frontaliers, communautés de sourds, entre autres. Toujours selon Savedra, les situations de contact ne sont pas absolues, mais relatives. Après la présentation de trois situations de contact rapportées par trois chercheurs appartenant à des institutions différentes, elles ont répondu brièvement à d'importantes questions des auditeurs sur le sujet abordé : la sociolinguistique de contact.

\section{PALAVRAS-CHAVE}

Sociolinguística de contato. Plurilinguismo. Diversidade etnolinguística.

\section{MOTS-CLÉS}

Sociolinguistique de contact. Plurilinguisme. Diversité ethnolinguistique.

No dia 11 de julho de 2020, as professoras Beatriz Christino, da Universidade Federal do Rio de Janeiro (UFRJ), Karen Pupp Spinassé, da Universidade Federal do Rio Grande do Sul (UFRGS) e Silvana Araújo, da Universidade Estadual de Feira de Santana (UEFS), apresentaram pesquisas sobre situações de contato na mesa redonda on-line no site da Abralin, Associação Brasileira de Linguística, cujos títulos seguem respectivamente: "A (inegável) diversidade das variedades de português indígena"; "Hunsrückisch: língua brasileira de imigração" e "Caracterização do português popular falado em comunidades rurais afro-brasileiras da Bahia e de Sergipe: documentos de comunidades de práticas afrobrasileiras para o estudo de contatos linguísticos". Em suas falas, as professoras trataram da relevância das situações de contato para cada contexto apresentado.

A primeira apresentação da mesa foi da professora Beatriz Christino, que ressaltou inicialmente a grave situação que os indígenas vêm enfrentando no atual desgoverno ${ }^{1} \mathrm{e}$, sobretudo, o impacto do COVID- $19^{2}$ sobre esses povos, que veem sua diversidade linguística e cultural ameaçada cotidianamente pelo ódio e pelo descaso.

Em sentido oposto, a pesquisadora nos apresenta a rica diversidade de diferentes povos indígenas, o que promove a reflexão sobre as diferentes formas de resistência e enfrentamento às incongruências de um país cada vez mais caracterizado por uma normatividade limitadora e destrutiva. A esse respeito, Anthias (2006) questiona: " [...] em que condições pessoas com diferentes idiomas,

1 Comentário da autora

2 "É uma doença causada pelo coronavírus SARS-CoV-2." 


\section{REVISTA DA ABRALIN}

culturas e modos de vida deixam de viver em harmonia?"3 Anthias ainda sublinha que é preciso entender a questão sobre outro ângulo, em que o foco estaria nas condições estruturais e políticas envolvidas, além de chamar a atenção para a necessidade de ir além da política de pertencimento e considerar a multiplicidade de identidades ao discutir questões de pertença.

Beatriz levanta algumas variedades do português falado por diversos povos indígenas da região do Alto Rio Negro, como a variedade Carajá, a Taperapé, povo que por sinal é trilíngue, o português Xinguano, a variedade Kamayurá, entre outras. Essas variedades apontam para um alto índice de identidade étnica, visto que são peculiares de cada povo e distintos do português brasileiro regional, das variedades mais conhecidas, pois apresentam traços fonéticos e morfossintáticos específicos. Entendemos que essa diversidade das variedades do português representa, a despeito daqueles que consideram o Brasil um país monolíngue, a riqueza e a importância da valorização deste evidente plurilinguismo. Com base nas observações de Savedra e Perez (2017), as pesquisas em contato linguístico vêm desconstruindo o mito do monolinguismo que configura a associação "um povo, um país, uma língua".

Dentre outras variedades apresentadas na fala da mesa, a pesquisadora cita que, na variedade do português Timbira, as particularidades vão além das fonéticas e morfossintáticas, ela destaca uma particularidade discursiva, que se caracteriza pelo uso de marcadores para iniciar e finalizar tópicos discursivos, apresentando alguns exemplos retirados de sua pesquisa, além de citar outra particularidade do português Kuikuro, que se define pelo emprego de um Code-Switching ${ }^{4}$ utilizado pelos homens com falantes não kuikuro, o que lhes coloca em posição de falantes multilíngues pertencentes a essa etnia, marcando sua identidade. Ao final, Beatriz também apresenta um pouco de sua pesquisa sobre o português Kaxinawá, povo indígena com maior população no Acre, e sua particularidade em marcar o plural na extremidade da direita no sintagma nominal, o que não acontece na variedade de falantes nativos do português brasileiro. Quanto a essa particularidade da língua Kaxinawá, propomos, a seguir, dois dos trechos citados por Beatriz:

\section{Ex: "tem que cuidar é nosso arrecurso naturais adentro da terra indígena" \\ Ex: "ensinar e a medici...erva medicinais}

A pesquisadora acredita que essa expressão de plural na extremidade da direita, esteja relacionada à maneira como se organiza a marcação de plural na língua Kaxinawá.

A segunda fala foi da professora Karen Spinassé, que abordou uma língua brasileira de imigração, o Hunsrückisch. A pesquisadora propôs uma breve definição de línguas de imigração ao considerálas como variedades introduzidas no Brasil por imigrantes. Em seguida, ela apresentou um quadro com povos que colonizaram os três estados do Sul do Brasil. Ao citar a existência de mais de 50 línguas de imigração no país, Karen afirma que 13 delas são de base germânica, e que uma delas é o

\footnotetext{
3 “[...] what conditions do peaple with diferente languages, cultures and ways of life fail to live in Harmony?" Tradução própria.

4 Alternância de código
} 


\section{REVISTA DA ABRALIN}

Hunsrückisch, que, embora a matriz seja muito semelhante à matriz de origem, de base alemã, o status da língua é de língua brasileira.

Atuante no campo da linguística aplicada, Karen apresenta um projeto de pesquisa do qual participou sobre o aprendizado do alemão standart como língua adicional em regiões de contato linguístico português-Hunsrückisch, que fomenta uma didática do multilinguismo pautada em atividades de conscientização e contrastividade linguísticas, usando os elementos do Hunsrückisch em prol do aprendizado do alemão standart, com o propósito de torná-lo mais bem sucedido e menos traumático. Nessa perspectiva, a pesquisadora menciona os conceitos de língua minoritária e língua minorizada, ao se referir aos preconceitos sofridos pelos falantes do Hunsrückisch, que têm a impressão de que falam uma língua "errada". Para Bagno (2017), diferente de minoritário, termo que remete a condições meramente quantitativas, a situação minorizada de uma língua é geralmente usada como uma prerrogativa para a restrição de direitos de uma determinada comunidade. Por seu turno, Lagares (2011, p. 171) afirma que a língua minorizada é representada por meio de suas carências, a ponto de ser frequentemente imaginada como uma não língua, definição que mais se aproxima da percepção dos falantes de Hunsrückisch, conforme apresentado por Karen.

A fim de contribuir para uma visão mais positiva sobre a língua, a professora participou de projetos dentro de escolas públicas como forma de legitimar a presença dessa língua. Apesar de alguns contratempos e resistência por parte de colegas professores de língua portuguesa, Karen informa que a recepção em torno do Hunsrückisch como língua ponte para o aprendizado do alemão standart foi bem aceito por outros integrantes da comunidade escolar e, sobretudo, pelos alunos participantes do projeto.

Dentre outros apontamentos, ela ainda destaca a metodologia utilizada para averiguar o grau de inteligibilidade entre o Hunsrückisch e o alemão standart em meio a seus alunos. O dado gerado por essa pesquisa quantitativa apresentou o seguinte resultado: 79,4\% dos sujeitos participantes não demonstraram dúvida ao serem expostos a frases nas duas línguas, o que denota um auto grau de inteligibilidade, termo que Salgado e Spinassé (2019, p.11) definem como uma equiparação ao termo intercompreensão. Contudo, este último já bastante atrelado à compreensão leitora de indivíduos confrontados com textos de uma língua próxima à sua, acrescentam as pesquisadoras. Afirmamos que a empreitada glotopolítica de valorização de línguas de imigração, como o Hunsrückisch, possa representar, para seus falantes, a sensação libertadora de poder falar sua língua com orgulho e sem receios.

Por último e não menos importante, a terceira fala foi conduzida pela professora Silvana Araújo, que discorreu sobre uma variedade popular do português brasileiro falado em comunidades rurais afro-brasileiras da Bahia e do Sergipe. Segundo Silvana, essas variedades apresentam traços de um português adquirido por meio de intensos contatos linguísticos. A pesquisa baseia-se na documentação de comunidades de práticas afro-brasileiras para o estudo na área. Para a professora, a motivação para a pesquisa gira em torno da necessidade de entender a realidade sociolinguística a partir da fala de moradores e descendentes de africanos e escravizados de comunidades quilombolas, que representam um espaço de resistência para estes grupos étnicos, historicamente marcados pelo 


\section{REVISTA DA ABRALIN}

racismo que, ao nosso ver, insiste em assolar a nossa sociedade, sobretudo em tempos de instabilidade política e, consequentemente, caos social.

Para Silvana, os trabalhos apresentados nesta mesa redonda se juntam a fim de assinalar a relevância de refletir sobre as línguas africanas, indígenas e de imigrantes europeus em prol da diversidade, o que, para nós, se dá por meio de políticas públicas e educacionais de fomento à valorização do plurilinguísmo. Segundo Vitor (2016, p.37) a globalização nos insere cada vez mais em contato com pessoas, suas línguas e culturas, do mundo inteiro. Essa conjuntura vem motivando uma leva de projetos de formação de indivíduos e comunidades bi/plurilíngues.

Por fim, podemos afirmar que a mesa reitera a importância de pesquisas cujo escopo seja a busca de outras significações e perspectivas para as diversas situações envolvendo a sociolinguística de contato, a fim de trazer benefícios e contribuições para a população brasileira como um todo.

\section{REFERÊNCIAS}

ANTHIAS, F. Belongings in a Globalising and Unequal World: rethinking translocations. University of East London, 2006.

BAGNO, M. Dicionário Crítico de Sociolinguística. 1. Ed. São Paulo: Parábola Editorial, 2017.

BAGNO, M; LAGARES, X. C. Políticas da norma e conflitos linguísticos. São Paulo: Parábola Editorial, 2011.

ESTUDOS de Sociolinguística de Contato no Brasil. Mesa redonda apresentada por Beatriz Christino, Karen Pupp Spinassé e Silvana Araújo [s.l., s.n], 2020. 1 vídeo (1h 49min 50s). Publicado pelo canal da Associação Brasileira de Linguística. Disponível em: https://www.youtube.com/watch?v=H6LTOEuS VU Acesso em 15 julho 2020.

SAVEDRA, M. M. G; PEREZ, G. M. H. Plurilinguismo: Praticas linguísticas de imigrantes brasileiros no Suriname. Niterói: Instituto de Letras UFF, 2017.

PUPP SPINASÉE, K.; SALGADO, B. M. Pesquisando a inteligibilidade entre o Hunsrückisch e o alemão standart. Contingentia, UFGRS, 2019.

VITOR, A. D. M. A. Educação bilíngue: uma cartografia e as particularidades de um caso brasileiro. Dissertação (Mestrado em estudos de linguagem), 140 f. UFF: Niterói, 2016. 